\title{
Characterization of lethal inhalational infection with Francisella tularensis in the common marmoset (Callithrix jacchus)
}

Correspondence

Michelle Nelson

mnelson@dstl.gov.uk

Received 18 March 2010

Accepted 16 June 2010

\author{
Michelle Nelson, ${ }^{1}$ Mark S. Lever, ${ }^{1}$ Rachel E. Dean, ${ }^{1}$ Victoria L. Savage, ${ }^{1}$ \\ F. Javier Salguero, ${ }^{2}$ Peter C. Pearce, ${ }^{1}$ Daniel J. Stevens ${ }^{1}$ \\ and Andrew J. H. Simpson ${ }^{1}$ \\ ${ }^{1}$ Biomedical Sciences, Defence Science and Technology Laboratory (Dstl), Porton Down, Salisbury, \\ Wiltshire SP4 OJO, UK \\ ${ }^{2}$ Veterinary Laboratories Agency, Weybridge, Addlestone, Surrey KT15 3NB, UK
}

\section{INTRODUCTION}

Francisella tularensis is a Gram-negative intracellular pathogen and the causative agent of tularaemia. The disease is prevalent in many countries in the northern hemisphere and is infectious by a number of routes (Ellis et al., 2002). Due to its high infectivity and virulence, $F$. tularensis has been developed previously for use as a bioweapon (Dennis et al., 2001) and is considered a Category A agent on the Centers for Disease Control and Prevention threat lists (CDC Emergency Preparedness and Response website; http://emergency.cdc.gov/agent/ agentlist-category.asp).

A number of animal models, mainly rodents, have been used to study disease pathogenesis, to understand the host immunology and to assess the efficacy of various therapeutic agents and vaccines. The majority of work to study the pathogenesis of tularaemia has used murine models of infection (Conlan et al., 2003; Green et al.,

Abbreviations: ALT, alanine aminotransferase; AST, aspartate aminotransferase; NK, natural killer; $T_{\mathrm{c}}$, core body temperature.
2005). BALB/c mice and C57BL/6 mice are susceptible to low doses (between 10 and 20 c.f.u.) of both F. tularensis subsp. tularensis and $F$. tularensis subsp. holarctica (formally known as type A and type B strains, respectively; Green et al., 2005).

Despite the valuable information obtained from rodent models, there are limitations. Generally, one main limitation of animal models of infectious diseases is the inability to predict human responses to pathogens or therapeutic compounds accurately (Herodin et al., 2005). There are advantages to using non-human primates to model infectious diseases; for tularaemia, primates are the only experimental animals that develop the characteristic skin ulcers and lymphadenitis of tularaemia, whilst other clinical features reflect human disease more readily than rodent models. There is a need to develop robust nonhuman primate models of infection to assess potential vaccines and therapies.

Marmosets have been demonstrated to be susceptible to tularaemia in two naturally occurring outbreaks in captive animals (Posthaus et al., 1998; Splettstoesser et al., 2007). 
The reported disease pathology corresponded to experimental infection in other non-human primates. We have demonstrated previously that marmosets are susceptible to experimental inhalational tularaemia and develop a lethal infection (Nelson et al., 2009). The aim of the current study was to characterize the progression of the disease in the marmoset to determine the suitability of the species as a model of human infection.

\section{METHODS}

Animals. Healthy, sexually mature common marmosets (Callithrix jacchus) were obtained from the Dstl Porton Down breeding colony and housed in female and vasectomized male pairs. Adult animals were aged between 19 and 84 months old and weighed between 354 and $506 \mathrm{~g}$ at the time of challenge. The animals were allowed free access to food and water, as well as environmental enrichment. Prior to use in challenge studies, animals were surgically implanted intraperitoneally with a Remo 200 device to record core body temperature $\left(T_{\mathrm{c}}\right)$, under general anaesthesia (ketamine/medetomidine/isofluorane). Data were transmitted from the devices at $10 \mathrm{~s}$ intervals to locally placed antennas and relayed to receivers. Data were analysed using eDacq software to provide a real-time and recordable $T_{\mathrm{c}}$. All animal studies were carried out in accordance with the UK Animals (Scientific Procedures) Act of 1986 and the Codes of Practice for the Housing and Care of Animals used in Scientific Procedures 1989. Following challenge with $F$. tularensis, all animals were handled under UK Advisory Committee on Dangerous Pathogens animal containment level 3 conditions within a half-suit isolator compliant with British Standard BS5726.

Bacterial strain and culture. Glycerol stocks of $F$. tularensis strain SCHU S4 were obtained from DynPort Vaccine Company LLC. Bacteria were recovered from the vial onto blood cysteine glucose agar (BCGA) plates and incubated at $37^{\circ} \mathrm{C}$ for $24 \mathrm{~h}$, prior to recovery into PBS ( $\mathrm{pH} 7.3$ ). The $\mathrm{OD}_{590}$ of the suspension was adjusted to 0.1 , equivalent to approximately $1 \times 10^{8}$ c.f.u. $\mathrm{ml}^{-1}, 1 \mathrm{ml}$ of which was used to inoculate $100 \mathrm{ml}$ modified cysteine partial hydrolysate broth. The broth was shaken at 180 r.p.m. for $48 \mathrm{~h}$ at $37^{\circ} \mathrm{C}$. Prior to challenge, the $\mathrm{OD}_{590}$ of the culture was adjusted to 0.1 and serially diluted in PBS to the appropriate concentration for challenge. Viable counts were performed by subculture onto BCGA retrospectively. Plates were incubated at $37{ }^{\circ} \mathrm{C}$ for $72 \mathrm{~h}$ prior to enumeration. All bacteriological procedures were carried out under UK Advisory Committee on Dangerous Pathogens containment level 3 conditions in Class 3 microbiological safety cabinets compliant with British Standard BS5726.

Challenge. The marmosets were anaesthetized with $25 \mathrm{mg}$ ketamine $\mathrm{kg}^{-1}$ administered intramuscularly prior to exposure and were challenged in pairs by the airborne route (Lever et al., 2008; Nelson et al., 2009). Briefly, a Collison nebulizer containing $20 \mathrm{ml} \mathrm{F}$. tularensis and three drops of Antifoam 289 (Sigma) was used to generate aerosol particles of approximately $1-3 \mu \mathrm{m}$. The aerosol was conditioned in a modified Henderson apparatus (Druett, 1969). Marmosets were placed in a head-only exposure chamber (plethysmograph tube) and exposed for $10 \mathrm{~min}$ to a dynamic aerosol maintained at $50-55 \%$ relative humidity and $18-20{ }^{\circ} \mathrm{C}$. The total accumulated tidal volume for each animal during challenge was determined by whole-body real-time plethysmography with a Fleisch pneumotachograph (EMMS). The concentration of the aerosol cloud was quantified after sampling from a sample port into an all-glass impinger (AGI-30; SKU) by serial dilution and plating onto BCGA.

Characterization of the disease. Ten marmosets were challenged in pairs with $F$. tularensis strain SCHU S4 by the airborne route (Table 1). Pairs of animals were sacrificed at 0, 24, 48, 72 and $96 \mathrm{~h}$ post-challenge to investigate disease progression trends. Blood was removed from marmosets immediately after culling by cardiac puncture for assessment of bacteraemia, clinical chemistry, haematology and immunology. Post-mortem examinations were performed on all animals upon culling; organs were removed and assessed for bacteriology, immunology, gross pathology and histopathology.

Bacteriology. Bacterial loads in the blood, liver, spleen, kidneys and lungs were assessed for all animals. Sacrificed animals were dissected, the organs were removed aseptically and the organ weight was determined. Organs were homogenized in $5 \mathrm{ml}$ PBS using cell sieves and a plunger. Organ homogenates and blood were serially diluted in PBS and the appropriate dilutions were subcultured onto BCGA plates, which were incubated at $37^{\circ} \mathrm{C}$ for $72 \mathrm{~h}$ prior to enumeration. Counts were expressed as c.f.u. (g tissue $)^{-1}$ or c.f.u. $(\mathrm{ml} \mathrm{blood})^{-1}$.

Cytokine and chemokine determination. Blood and organ homogenates were also processed for immunological analysis. For cytokine and chemokine analysis, the cell suspension supernatants were collected and stored at $-80{ }^{\circ} \mathrm{C}$ until assayed. A range of cytokines appropriate for qualification of an innate response was measured. The cytokines were assayed using a Cytometric Bead Array Flex Set (BD Biosciences) according to the manufacturer's instructions. Briefly, cytokine standards were reconstituted in assay buffer diluent (buffered protein solution) and serially diluted. Ten

Table 1. Animal and exposure dose data

\begin{tabular}{|c|c|c|c|c|c|c|}
\hline $\begin{array}{l}\text { Time of } \\
\text { culling (h) }\end{array}$ & Gender & $\begin{array}{c}\text { Age } \\
\text { (years) }\end{array}$ & $\begin{array}{c}\text { Body } \\
\text { weight }(\mathrm{g})\end{array}$ & $\begin{array}{c}\text { Inhaled accumulative } \\
\text { volume }(1)\end{array}$ & $\begin{array}{c}\text { Aerosol } \\
\text { concn }\left(\text { c.f.u. } 1^{-1}\right)\end{array}$ & $\begin{array}{c}\text { Inhaled } \\
\text { dose (c.f.u.) }\end{array}$ \\
\hline \multirow[t]{2}{*}{0} & $\mathrm{~F}$ & 4.8 & 374 & 0.8 & $2.9 \times 10^{2}$ & $2.2 \times 10^{2}$ \\
\hline & M & 7.0 & 382 & 1.0 & $2.9 \times 10^{2}$ & $2.8 \times 10^{2}$ \\
\hline \multirow[t]{2}{*}{24} & $\mathrm{~F}$ & 2.2 & 426 & 1.3 & $1 \times 10^{2}$ & $1.3 \times 10^{2}$ \\
\hline & M & 5.0 & 442 & 1.8 & $1 \times 10^{2}$ & $1.8 \times 10^{2}$ \\
\hline \multirow[t]{2}{*}{48} & $\mathrm{~F}$ & 2.1 & 506 & 1.5 & $1.6 \times 10^{2}$ & $2.4 \times 10^{2}$ \\
\hline & M & 3.8 & 390 & 1.1 & $1.6 \times 10^{2}$ & $1.8 \times 10^{2}$ \\
\hline \multirow[t]{2}{*}{72} & $\mathrm{~F}$ & 1.6 & 404 & 2.0 & $8.7 \times 10^{1}$ & $1.7 \times 10^{2}$ \\
\hline & M & 2.2 & 394 & 1.1 & $8.7 \times 10^{1}$ & $9.2 \times 10^{1}$ \\
\hline \multirow[t]{2}{*}{96} & $\mathrm{~F}$ & 1.8 & 354 & 1.0 & $1.6 \times 10^{2}$ & $1.6 \times 10^{2}$ \\
\hline & M & 2.2 & 470 & 0.9 & $1.6 \times 10^{2}$ & $1.4 \times 10^{2}$ \\
\hline
\end{tabular}


microlitres of each cytokine capture bead suspension per test was mixed and transferred to the assay tubes. The test sera or standard dilutions and phycoerythrin detection reagent $(50 \mu \mathrm{l})$ were added to sample tubes and incubated for $2 \mathrm{~h}$ in the dark. The samples were then washed with $1 \mathrm{ml}$ wash buffer (PBS, protein and detergent) and centrifuged. One millilitre of $4 \%$ paraformaldehyde was added to each tube for fixation at $4{ }^{\circ} \mathrm{C}$ for $24 \mathrm{~h}$ prior to analysis. Cytokine detection was performed by flow cytometry on a BD FACSCanto using BD FACSDiva and FACScan software. Cytokine and chemokine levels were expressed as $\mathrm{pg} \mathrm{ml}^{-1}$, except for monocyte chemotactic protein-1 (MCP-1), which was expressed as fluorescence intensities, as, due to the failure of the standard antibody, a calibration curve was not determined.

Cell type determination. Cell type was assessed from the fresh cell suspension. A range of anti-human monoclonal antibodies was used for lymphocyte staining according to the manufacturer's concentrations: anti-CD3 (clone sp34; BD Biosciences), anti-CD4 (clone MT310; Dako), anti-CD8 (clone lt8; AbD Serotec), anti-CD11c (clone s-hcl-3; BD Biosciences), anti-CD14 (clone m5e2; BD Biosciences), anti-CD20 (clone B-Ly1; Dako), anti-CD27 (clone m-t271; BD Biosciences), anti-CD56 (clone NCAM16.2; BD Biosciences) and anti-V $\gamma 2$ (15D; Endogen) stain. Single-cell homogenate or whole blood $(100 \mu \mathrm{l})$ was stained using these fluorescently labelled antibodies, which have previously been reported as cross-reacting with marmoset leukocytes (Brok et al., 2001). After staining for $40 \mathrm{~min}$ at room temperature in the dark, red blood cells were lysed using OptiLyse C (Beckman Coulter), washed and resuspended in $4 \%$ paraformaldehyde and kept at $4{ }^{\circ} \mathrm{C}$ for $24 \mathrm{~h}$ before being analysed on a six-colour BD FACSCanto II using FACSDiva software. Data for 10000 events of appropriate proportions for live leukocytes were collected. Briefly, leukocytes were defined by appropriate location and the following staining: $\mathrm{CD}^{+}$as $\mathrm{T}$ cells, $\mathrm{CD}^{+} \mathrm{CD}^{+} \mathrm{CD}^{+} 6^{+}$as activated cytotoxic $\mathrm{T}$ cells, $\mathrm{CD} 3^{+} \mathrm{CD} 8^{-}$as $\mathrm{CD} 4 \mathrm{~T}$ cells, $\mathrm{CD} 3^{+} \mathrm{V} \gamma 2^{+}$ $\mathrm{CD} 6^{+}$as activated $\gamma \delta \mathrm{T}$ cells, $\mathrm{CD} 3^{+} \mathrm{CD}^{+} 6^{+} \mathrm{CD} 8^{-}$as natural killer (NK) $\mathrm{T}$ cells, $\mathrm{CD}^{-} \mathrm{CD}^{+} 6^{+}$as $\mathrm{NK}$ cells, CD14 ${ }^{+} \mathrm{CD}_{11 c^{-}}$as neutrophils, $\mathrm{CD} 14^{+} \mathrm{CD} 11 \mathrm{c}^{+}$as macrophages and $\mathrm{CD} 20^{+}$as B cells. Cell type levels were expressed as a percentage of the viable population.

Due to the small group sizes, statistical analysis was not possible. Only increases in percentages of cells to twice that of the normal mean (obtained from three uninfected animals) and outside the ranges are reported.

Histopathology. Tissues were fixed in $10 \%$ neutral buffered formalin and processed for paraffin wax embedding using standard techniques. Thin sections $(5 \mu \mathrm{m})$ were cut and stained with haematoxylin and eosin for histopathological analysis.

Haematology, clinical chemistry and electrolytes. Blood was collected at defined time points into tubes containing EDTA and key parameters were measured by use of a laser flow cytometry-based haematological analyser (LaserCyte; IDEXX Laboratories): total white blood cell count, platelet count, packed cell volume (haematocrit) and haemoglobin. Plasma (lithium heparin) concentrations of albumin, alkaline phosphatase, total bilirubin, alanine aminotransferase (ALT), aspartate aminotransferase (AST), creatine kinase, glucose and creatinine were determined using a 'dry-slide' technology biochemistry analyser (VetTest; IDEXX Laboratories). An ion-selective electrode-based electrolyte analyser (VetLyte; IDEXX Laboratories) was used to measure $\mathrm{K}^{+}$and $\mathrm{Na}^{+}$concentrations. Post-challenge data were compared with the mean data from the same group of animals analysed pre-challenge.

Statistics. Pearson's correlation analysis was used to determine the relationship of gender, body weight, time to death and inhaled dose.

\section{RESULTS AND DISCUSSION}

The aim of this study was to examine disease progression trends in marmosets following an inhalational challenge with $F$. tularensis. Ethical considerations necessarily limited group sizes, but the study design none the less provided useful data. Animals were challenged with $\sim 10^{2}$ c.f.u. $F$. tularensis and culled at specific time points post-challenge (Table 1). Previous data have shown that marmosets challenged in this dose range die between 4.5 and 7 days post-challenge and that there is no statistical correlation between the age, weight or gender of marmosets and susceptibility to inhalational tularaemia (Nelson et al., 2009). The course of infection was described in terms of temperature profile, clinical signs of infection, cytokine profile (data not shown), bacteriology (Fig. 1), immune cell populations (Fig. 2), histopathology (Fig. 3), and haematology and clinical parameters.

\section{Early disease (0-48 h)}

Mild pathological features, including mild enlargement of the inter-alveolar septa, were observed in the lungs of one animal culled immediately after challenge due to the aerosol exposure process. Other minimal foci of inflammatory mononuclear cell infiltrations in the kidney and liver were also considered to be background pathology.

During the early disease, animals appeared normal with no apparent clinical signs or changes in behaviour and had a normal $T_{\mathrm{c}}$. On post-mortem, some slight haemorrhagic lesions were apparent in the lungs of both animals at $24 \mathrm{~h}$ post-challenge, which may have been as a result of the blood withdrawal via cardiac puncture. There was no evidence of gross pathology in any other organs. At $48 \mathrm{~h}$ post-challenge, both animals exhibited splenomegaly, with slight hepatomegaly in the male and enlarged lungs in the female. Minor histopathology was observed in all these animal tissues, such as small areas of emphysema in the lungs, as well as other signs considered to be background histopathology.

At $24 \mathrm{~h}$ post-challenge, bacteria were recovered only from the lungs of animals, with increasing numbers by $48 \mathrm{~h}$ post-challenge, when there were also low levels of bacteria recovered in the spleen (Fig. 1).

Baseline haematological and biochemical parameters for the marmosets used in this study were comparable to previously reported data (Yarbrough et al., 1984). Notable blood parameter changes at $24 \mathrm{~h}$ post-challenge included: slightly raised neutrophil percentage counts to $57.5 \%$ (but not total white blood cell counts) compared with pre-challenge baselines of $42 \%$, a lowered platelet count to $434 \times 10^{3} \mu \mathrm{l}^{-1}$ (baseline value of $499 \times 10^{3} \mu^{-1}$ ) and significantly elevated glucose concentrations to $340 \mathrm{mg} \mathrm{dl}^{-1}$ (baseline value of $197 \mathrm{mg} \mathrm{dl}^{-1}$ ), plus altered liver enzyme results (elevated ALT to $89 \mathrm{U} \mathrm{l}^{-1}$ and elevated AST to $586 \mathrm{U} \mathrm{l}^{-1}$ compared with baseline values of 11 and $134 \mathrm{U} \mathrm{l}^{-1}$, respectively). Changes in blood parameters at $48 \mathrm{~h}$ post-challenge included elevated bilirubin to $0.8 \mathrm{mg} \mathrm{dl}^{-1}$ (baseline value of 0.4 ). 


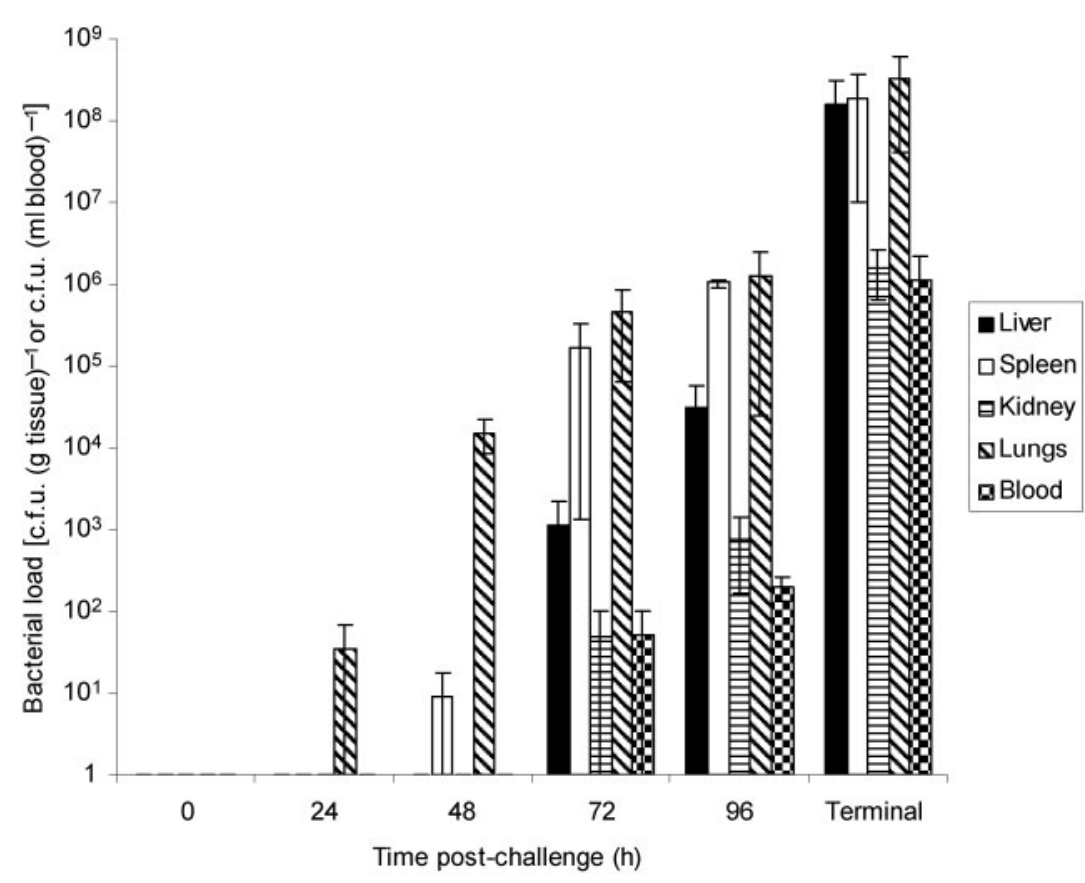

Fig. 1. Bacterial load isolated from selected marmoset organs at different times postchallenge with $\sim 10^{2}$ c.f.u. inhalational $F$. tularensis $[n=2$ for all time points, except terminal animals where $n=6$ (samples obtained from a previous study; Nelson et al., 2009)].

In order to assess the immune response in marmosets, antihuman antibodies were successfully used to detect and identify marmoset cell types and cytokines as described previously (Brok et al., 2001). Flow cytometry analysis showed an increase in MCP-1 levels (not shown) and the proportion of neutrophils in the lung at $24 \mathrm{~h}$ post- (a)

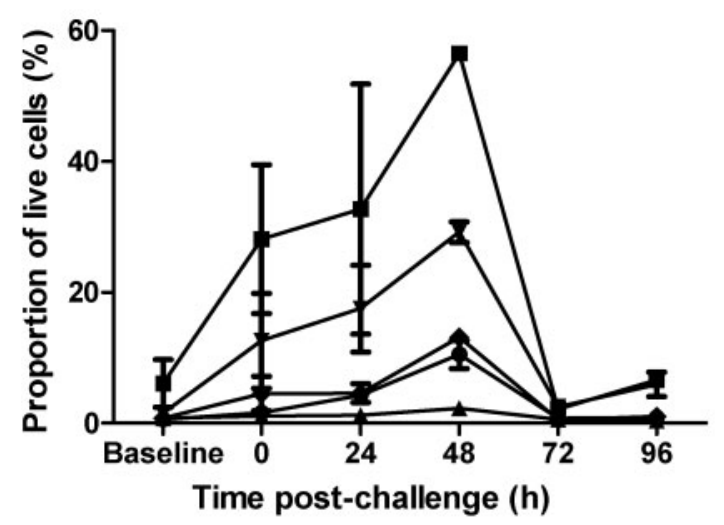

(b)

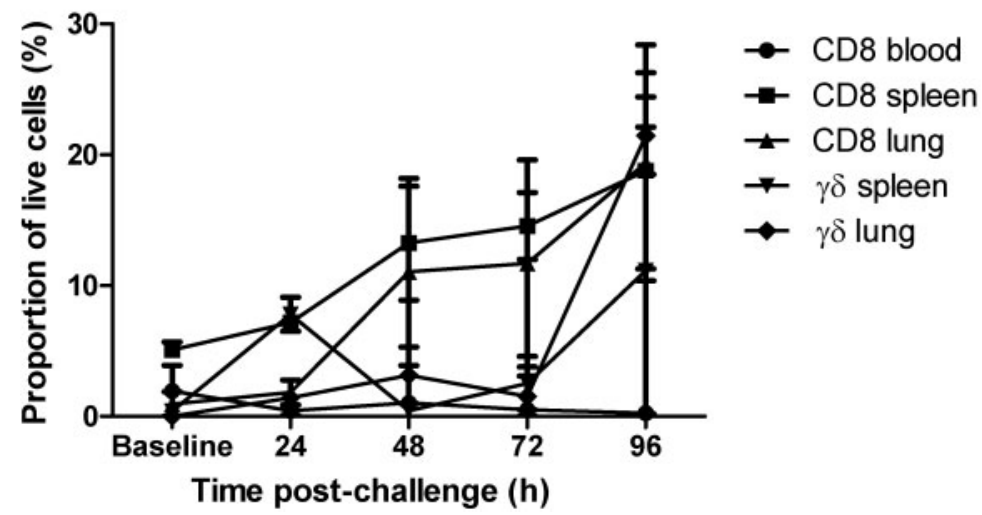

$\rightarrow$ T cells

$\rightarrow$ NK cells

$\rightarrow$ Neutrophils

$\neg$ Macrophages $\leftarrow$ B cells
Fig. 2. Cellular populations isolated from selected marmoset organs at different times after challenge with $\sim 10^{2}$ c.f.u. inhalational $F$. tularensis $[n=2$ for all time points, except naïve control animals (baseline values) where $n=3$ ]. (a) Lymphocyte populations in the lung. (b) Tcell summary. 

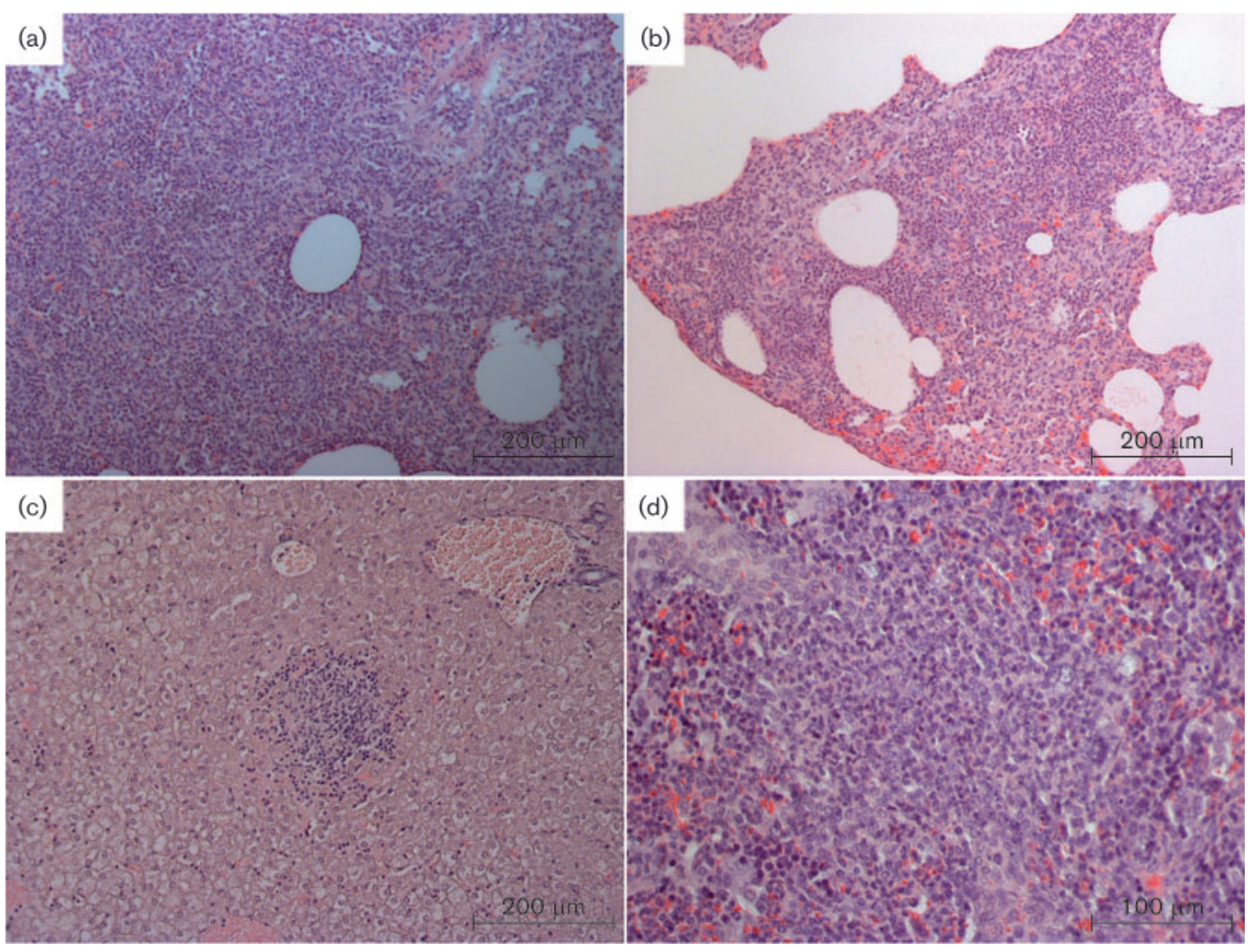

Fig. 3. Haematoxylin and eosin-stained sections from marmosets infected with $\sim 10^{2}$ c.f.u. F. tularensis by the airborne route. (a) Lung section from a marmoset at $72 \mathrm{~h}$ after challenge by the airborne route showing focal pneumonia. (b) Lung section from a marmoset at $96 \mathrm{~h}$ post-challenge showing extensive bronchopneumonia. (c) Liver section from a marmoset at $96 \mathrm{~h}$ postchallenge showing necrotizing hepatitis with the formation of microabscesses. (d) Spleen section from a marmoset at $96 \mathrm{~h}$ post-challenge showing necrotizing splenitis with the formation of microabscesses. Magnification: $\times 100(a-c) ; \times 200(d)$.

challenge (Fig. 2a). By $48 \mathrm{~h}$ post-challenge, an increase in the number of neutrophils in the lungs (Fig. 2a) and blood (not shown) was observed to approximately $30 \%$. Increases in the percentages of NK cells and macrophages (57 and 13\%) were also observed in the lungs (and an increase in T cells to $11 \%$ ) (Fig. 2a), with an increase in T and $\mathrm{B}$ cells in the spleen to 23 and $19 \%$, respectively (not shown). There was also an increase in the percentage of $\mathrm{CD}^{+} \mathrm{T}$ cells in the spleen and lungs to 13 and $11 \%$, respectively, with a slight increase in the proportion of the $\gamma \delta$ T-cell population in the lung to approximately $3 \%$ (Fig. 2b).

\section{Overt disease (72 h onwards)}

No overt clinical signs were apparent in any of the animals until $96 \mathrm{~h}$ post-challenge, when they were subdued in nature, with some slight piloerection. Animals that died from infection or were culled due to severe infection (between 4.5 and 7 days post-challenge) generally presented with a progression of overt clinical signs of infection including lethargy, piloerection, and unsteadiness or slowness of movement (Nelson et al., 2009). The first indication of infection in the marmoset is a rapid increase in body temperature, which occurred in this study at $72 \mathrm{~h}$ postchallenge. At this time, the mean $T_{\mathrm{c}}$ increased from 38.8 to $39.6{ }^{\circ} \mathrm{C}$ for the male and from 38.5 to $40.4{ }^{\circ} \mathrm{C}$ for the female. The temperatures continued to increase, and by $96 \mathrm{~h}$ postchallenge the $T_{\mathrm{c}}$ of the animals remained consistently high (greater than $40{ }^{\circ} \mathrm{C}$ ) for at least 2 days. The time to onset of fever in humans is similar and has been shown to occur at 3-6 days post-exposure (Evans et al., 1985; Saslaw et al., 1961). The increase in temperature at this time in the marmoset infection coincided with a number of other factors. There was a rapid increase in the number of bacteria isolated from all organs tested (Fig. 1), a more pronounced gross pathology and histopathology, and an increase in the immunological responses. The bacteria spread from the lungs to the reticuloendothelial system (initially the spleen, followed by the liver), with significant numbers in all organs assessed at $96 \mathrm{~h}$ observed in the marmoset, as has also been observed in murine and human infections (Conlan et al., 2003; Gill \& Cunha, 1997).

Histology. The small areas of lesions observed at earlier times in the lung, liver, spleen and lymph tissue developed 
into focal areas of pyogenic lesions (particularly pyogranulomatous pneumonia) by $72 \mathrm{~h}$ post-challenge (Fig. 3a). This developed to pyogranulomatous pneumonia in the lungs by $96 \mathrm{~h}$, with multifocal to coalescent inflammation apparent in one animal (Fig. 3b). Animals also exhibited necrosis in the draining lymph nodes (lymphadenitis), hepatitis, splenitis and interstitial pneumonia by $96 \mathrm{~h}$ post-challenge (Fig. 3c, d). The primary infiltrating cell type was neutrophils, but lymphocytes, macrophages and plasma cells were also identified. This pathology, including pyogranulomatous pneumonia, interstitial pneumonia, organ necrosis and the influx of neutrophils and macrophages into tissue, is also seen in human infection (Avery \& Barnett, 1967; Martin \& Marty, 2001; Syrjala et al., 1986). Other pathological features reported in human infections were also observed in the marmosets, including thrombosis, giant cells and lung oedema (Martin \& Marty, 2001; Syrjala et al., 1986).

Immunology. The type of immune response elicited by the marmosets in response to $F$. tularensis infection was indicated by the cytokine levels detected. Generally, cytokine levels increased with disease progression, with the highest levels in animals that were culled as a result of severe infection (terminal animals). Levels of MCP-1 were detected for the first time in the spleen, blood and lungs at $72 \mathrm{~h}$ post-challenge $\left(1.1 \times 10^{3}, 1.15 \times 10^{3}\right.$ and $1 \times 10^{3} \mathrm{pg}$ $\mathrm{ml}^{-1}$, respectively). The levels further increased in all organs until just prior to death, reaching more than $5000 \mathrm{pg} \mathrm{ml} \mathrm{m}^{-1}$. By $96 \mathrm{~h}$ post-challenge, there was an increase in the concentration of macrophage inflammatory protein $1 \alpha$ (MIP- $1 \alpha)$, MIP- $1 \beta$, MCP-1, interleukin-6 (IL-6), RANTES and IL-1 $\beta$ present in all organs. The presence of MIP- $1 \alpha$ and IL- 6 was first observed in animals prior to death. The detection of IL-6 in animals shortly before death is also observed in mice following inhalational challenge (Conlan et al., 2008). The cytokine response observed was consistent with the attraction of macrophages, immature dendritic cells, basophils and lymphocytes to sites of infection and the production of fever, sepsis and tissue necrosis.

The first cell types to reach the sites of infection were the neutrophils and NK cells at $24 \mathrm{~h}$ post-challenge, followed by macrophages, NK cells and $\mathrm{T}$ cells at $48 \mathrm{~h}$ postchallenge. By $72 \mathrm{~h}$ post-challenge, there was a decrease in the percentage of neutrophils in the blood and lungs to 23 and $3 \%$, respectively (Fig. 2a and data not shown), which returned to within normal parameters by $96 \mathrm{~h}$ postchallenge. The role of neutrophils in F. tularensis infection is unclear; it has been shown that they are essential in murine survival by reducing the bacterial burden in organs (Sjöstedt et al., 1994). This is despite evidence to suggest that, although $F$. tularensis is readily taken up by neutrophils, they are unable to kill the pathogen. This study indicated that, despite a large increase in the neutrophil population at $48 \mathrm{~h}$ post-challenge, there was no apparent control of bacterial numbers; indeed, the bacterial load in each organ tested rapidly increased after this time. The rapid increase in the neutrophil population reported here in the early response to tularaemia infection has been shown in BALB/c mice in response to type $B$ but not type A strains (Hall et al., 2008). Failure of the F. tularensis strain SCHU S4 to repress neutrophil recruitment may reflect a basic difference between the murine and a more resistant animal model, indicating that the marmoset may provide a more representative model for the human disease. The reduction in neutrophil numbers at $72 \mathrm{~h}$ post-challenge may be due to the destruction of these cells, particularly in the lungs.

At $72 \mathrm{~h}$ post-challenge, there was also a decrease in the percentage of all cell types in the lungs including a decrease in NK cells to $2 \%$, and a decrease in T and B cells and macrophage populations to less than $1 \%$ each (Fig. 2a). There was an increase in the $\mathrm{T}$ and $\mathrm{B}$ cell populations in the spleen to 27 and $29 \%$, respectively, and also in the blood to 23 and $12 \%$ (data not shown). By $96 \mathrm{~h}$ post-challenge, the percentage of most cell types had returned within normal parameters in all organs (Fig. 2a and data not shown). However, there was a further increase in the number of $\mathrm{CD}^{+} \mathrm{T}$ cells in the spleen and lung, and, most interestingly, there was a large increase in the $\gamma \delta \mathrm{T}$-cell population in these organs (Fig. $2 \mathrm{~b}$ ). $\gamma \delta \mathrm{T}$ cells are known to accumulate at sites of infection and are thought to act as a first line of defence against certain intracellular pathogens. They have been linked repeatedly with Francisella infections in humans (Kroca et al., 2000; Poquet et al., 1998; Sumida et al., 1992). However, it is not clear whether this increase is linked to survival or infection. In the current study, there was no observable increase in the $\gamma \delta \mathrm{T}$ cell population in the blood, although marked increases in the spleen and lungs were observed. It is not surprising that the cell numbers initially increased at the site of infection, prior to circulation. Indeed, increases in the $\gamma \delta \mathrm{T}$-cell population in the blood of patients suffering from ulceroglandular tularaemia were not detected until 1 week after infection (Kroca et al., 2000).

Blood parameters. Notable changes in the physiological state of the animal included an increase in creatine kinase levels at $72 \mathrm{~h}$ post-challenge, plus further evidence of altered liver function (elevated AST in both animals, and raised ALT in the female). By $96 \mathrm{~h}$ post-challenge, further changes included elevated white blood cell counts to $14.3 \times 10^{3} \mu^{-1}$ from baseline values of $9.3 \times 10^{3} \mu \mathrm{l}^{-1}$, a lowered platelet count in the male to $276 \times 10^{3} \mu^{-1}$ from baseline values of $499 \times 10^{3} \mu \mathrm{l}^{-1}$ and significantly raised plasma glucose and potassium to $685 \mathrm{mg} \mathrm{dl}^{-1}$ and $11.4 \mathrm{mmol} \mathrm{l}^{-1}$ from baseline levels of $197 \mathrm{mg} \mathrm{dl}^{-1}$ and $3.9 \mathrm{mmol}^{-1}$, respectively. In animals that died or were culled due to severe infection, significantly reduced platelet counts and plasma glucose concentrations were noted from $499 \times 10^{3} \mu \mathrm{l}^{-1}$ and $197 \mathrm{mg} \mathrm{dl}^{-1}$ to $49 \times 10^{3} \mu \mathrm{l}^{-1}$ and $29 \mathrm{mg} \mathrm{dl}{ }^{-1}$, respectively. There were also significantly elevated creatine kinase levels and raised levels of liver 
function enzymes (including bilirubin), plus a raised plasma creatinine level. These changes in blood parameters, although limited by the small number of animals studied at each time point, were consistent with the onset of systemic infection. Changes in plasma glucose, creatine kinase, liver function enzymes and platelets, as well as no change to haemoglobin levels, have been observed previously in tularaemia patients (Evans et al., 1985; Kaiser et al., 1985).

In conclusion, experimental acute inhalational tularaemia in the common marmoset appears to be representative of the infection seen in humans. Clinical presentation, bacterial spread, pathology and haematological, biochemical and immunological changes (including increased $\gamma \delta \mathrm{T}$ cells) are similar between both species. These findings suggest that the common marmoset may be a suitable animal model of inhalational tularaemia, which may be useful for the investigation of novel medical interventions such as vaccines and therapeutics.

\section{ACKNOWLEDGEMENTS}

This project was funded with federal funds from the National Institute of Allergy and Infectious Diseases (NIAID), under contract no. N01AI-30062 through our Prime Contractor, the Health Protection Agency (HPA), Porton Down, UK, and the authors would like to thank Allen Roberts and Dr Kristin DeBord for their support. The authors would like to thank all Dstl employees who helped support this work, including Chris Taylor and Jan Platt for histopathological support. We also would like to thank Donna Hopkins and Graham Hatch at the HPA for performing the clinical analysis on blood.

\section{REFERENCES}

Avery, F. W. \& Barnett, T. B. (1967). Pulmonary tularemia. A report of five cases and consideration of pathogenesis and terminology. Am Rev Respir Dis 95, 584-591.

Brok, H. P. M., Hornby, R. J., Griffiths, G. D., Scott, L. A. M. \& Hart, B. A. (2001). An extensive monoclonal antibody panel for the phenotyping of leukocyte subsets in the common marmoset and the cotton-top tamarin. Cytometry 45, 294-303.

Conlan, J. W., Chen, W., Shen, H., Webb, A. \& KuoLee, R. (2003). Experimental tularemia in mice challenged by aerosol or intradermally with virulent strains of Francisella tularensis: bacteriologic and histopathologic studies. Microb Pathog 34, 239-248.

Conlan, J. W., Zhao, X., Harris, G., Shen, H., Bolanowski, M., Rietz, C., Sjostedt, A. \& Chen, W. (2008). Molecular immunology of experimental primary tularemia in mice infected by respiratory or intradermal routes with type A Francisella tularensis. Mol Immunol 45, 2962-2969.

Dennis, D. T., Inglesby, T. V., Henderson, D. A., Bartlett, J. G., Ascher, M. S., Eitzen, E., Fine, A. D., Friedlander, A. M., Hauer, J. \& other authors (2001). Tularemia as a biological weapon - medical and public health management. JAMA 285, 2763-2773.

Druett, H. A. (1969). A mobile form of the Henderson apparatus. J Hyg (Lond) 67, 437-448.

Ellis, J., Oyston, P. C. F., Green, M. \& Titball, R. W. (2002). Tularemia. Clin Microbiol Rev 15, 631-646.

Evans, M. E., Gregory, D. W., Schaffner, W. \& McGee, Z. A. (1985). Tularemia: a 30-year experience with 88 cases. Medicine (Baltimore) 64, 251-269.
Gill, V. \& Cunha, B. A. (1997). Tularemia pneumonia. Semin Respir Infect 12, 61-67.

Green, M., Choules, G., Rogers, D. \& Titball, R. W. (2005). Efficacy of the live attenuated Francisella tularensis vaccine (LVS) in a murine model of disease. Vaccine 23, 2680-2686.

Hall, J. D., Woolard, M. D., Gunn, B. M., Craven, R. R., Taft-Benz, S., Frelinger, J. A. \& Kawula, T. H. (2008). Infected-host-cell repertoire and cellular response in the lung following inhalation of Francisella tularensis Schu S4, LVS, or U112. Infect Immun 76, 5843-5852.

Herodin, F., Thullier, P., Garin, D. \& Drouet, M. (2005). Nonhuman primates are relevant models for research in haematology, immunology and virology. Eur Cytokine Netw 16, 104-116.

Kaiser, A. B., Rieves, D., Price, A. H., Gelfand, M. R., Parrish, R. E., Decker, M. D. \& Evans, M. E. (1985). Tularemia and rhabdomyolysis. JAMA 253, 241-243.

Kroca, M., Tärnvik, A. \& Sjöstedt, A. (2000). The proportion of circulating $\gamma \delta \mathrm{T}$ cells increases after the first week of onset of tularaemia and remains elevated for more than a year. Clin Exp Immunol 120, 280-284.

Lever, M. S., Stagg, A. J., Nelson, M., Pearce, P., Stevens, D. J., Scott, E. A. M., Simpson, A. J. H. \& Fulop, M. J. (2008). Experimental respiratory anthrax infection in the common marmoset (Callithrix jacchus). Int J Exp Pathol 89, 171-179.

Martin, G. J. \& Marty, A. M. (2001). Clinicopathologic aspects of bacterial agents. Clin Lab Med 21, 513-548.

Nelson, M., Lever, M. S., Savage, V. L., Salguero, F. J., Pearce, P. C., Stevens, D. J. \& Simpson, A. J. H. (2009). Establishment of lethal inhalational infection with Francisella tularensis (tularemia) in the common marmoset (Callithrix jacchus). Int J Exp Pathol 90, 109118.

Poquet, Y., Kroca, M., Halary, F., Stenmark, S., Peyrat, M.-A., Bonneville, M., Fournié, J. J. \& Sjöstedt, A. (1998). Expansion of $\mathrm{V} \gamma 9 \mathrm{~V} \delta 2 \mathrm{~T}$ cells is triggered by Francisella tularensis-derived phosphoantigens in tularemia but not after tularemia vaccination. Infect Immun 66, 2107-2114.

Posthaus, H., Welle, M., Morner, T., Nicolet, J. \& Kuhnert, P. (1998). Tularemia in a common marmoset (Callithrix jacchus) diagnosed by 16S rRNA sequencing. Vet Microbiol 61, 145-150.

Saslaw, S., Eigelsbach, H. T., Prior, J. A., Wilson, H. E. \& Carhart, S. (1961). Tularemia vaccine study. II. Respiratory challenge. Arch Intern Med 107, 702-714.

Sjöstedt, A., Conlan, J. W. \& North, R. J. (1994). Neutrophils are critical for host defense against primary infection with the facultative intracellular bacterium Francisella tularensis in mice and participate in defense against reinfection. Infect Immun 62, 2779-2783.

Splettstoesser, W. D., Mätz-Rensing, K., Seibold, E., Tomaso, H., Al Dahouk, S., Grunow, R., Essbauer, S., Buckendahl, A., Finke, E.-J. \& Neubauer, H. (2007). Re-emergence of Francisella tularensis in Germany: fatal tularaemia in a colony of semi-free-living marmosets (Callithrix jacchus). Epidemiol Infect 135, 1256-1265.

Sumida, T., Maeda, T., Takahashi, H., Yoshida, S., Yonaha, F., Sakamoto, A., Tomioka, H. \& Koike, T. (1992). Predominant expansion of $\mathrm{V} \gamma 9 / \mathrm{V} \delta 2 \mathrm{~T}$ cells in a tularemia patient. Infect Immun 60, 2554-2558.

Syrjala, H., Sutinene, S., Jokinen, K., Nieminen, P., Tuuponen, T. \& Salminen, A. (1986). Bronchial changes in airborne tularemia. J Laryngol Otol 100, 1169-1176.

Yarbrough, L. W., Tollett, J. L., Montrey, R. D. \& Beattie, R. J. (1984). Serum biochemical, hematological and body measurement data for common marmosets (Callithrix jacchus jacchus). Lab Anim Sci 34, 276-280. 